\title{
Characteristics of graphene-layer encapsulated nanoparticles fabricated using laser ablation method
}

\author{
Q. Ou, T. Tanaka, M. Mesko, A. Ogino, and M. Nagatsu \\ Graduate School of Science and Technology, Shizuoka University, \\ 3-5-1 Johoku, Naka-ku, Hamamatsu, 432-8561, Japan
}

\begin{abstract}
Graphene layer-encapsulated $\mathrm{Ni}$ nanoparticles with diameters between 3 and $10 \mathrm{~nm}$ were fabricated by laser ablation techniques and deposited directly on the Si substrate at room temperature. It was found from the field-emission type scanning electron microscopy (FE-SEM) and transmitted electron microscopy(TEM) analyses that any carbon nanotubes were not fabricated in the deposited nano-materials. High-resolution TEM observation showed the core-shell structure of Ni-C particles with crystalline nickel core surrounded by graphite-like layers. The X-ray diffraction(XRD) pattern also revealed that nanoparticles embedded in graphene capsules are crystalline nickel. With these Ni-C nanoparticles, we demonstrated the growth of vertically aligned carbon nanotubes with low spatial density on a silicon substrate by DC plasma CVD.
\end{abstract}

Keywords: C-Ni nanoparticle; Graphene layer; Laser ablation; Carbon nanotube, Plasma CVD 


\section{Introduction}

Metal nanoparticles have extensive technological applications as super-high density magnetic recording media, medical imaging media, ferrofluids, catalysts, advanced electronics and optics devices [1-13] because of their unique properties differing from the corresponding bulk materials. The high surface-to-volume ratio, however, makes the naked metal nanoparticles unstable under air atmosphere [14-15]. Because of their good chemical and thermal stability, encapsulated metal nanoparticles have attracted increasing attention as an alternative to naked metal nanoparticles. Inertial encapsulation shell was confirmed very good to protect the core metal nanoparticles from air degradation. Many inertial encapsulation metal core-shell systems, such as $\mathrm{Ni}(\mathrm{Co}, \mathrm{Fe}, \mathrm{Ti}, \mathrm{Pd}, \mathrm{Pt}$ )-C

$\left(\mathrm{AlO}_{3}, \mathrm{BN}, \mathrm{Si}\right.$ ), have been developed by different techniques, such as modified arc discharge [2-7, 10,16-19], ion beam co-sputtering [11,20-21], and pulse laser ablation [22,23]. Among them, metal-carbon (M-C) system attracted the most attention because of the well-developed techniques for synthesizing carbon capsulation since the discovery of fullerenes and carbon nanotubes [24,25]. So far, we have reported the characteristics of graphene layer-encapsulated $\mathrm{Ni}$ nanoparticles prepared by using dc arc discharge [26]. These Ni-C nanoparticles have some attractive characteristics, that is, they keep their original encapsulated spherical structures even after heating at $900^{\circ} \mathrm{C}$. Hence we can use them as catalyst for growth of narrow CNTs [26].

M-C nanoparticles can be fabricated by arc discharge method [2-7, 10,16-19, 26], but they usually had big sizes and a broad distribution of particle sizes, in some cases empty carbon cages and carbon nanotubes were accompanied. Small size and uniform distribution of M-C particles were synthesized by annealing a M-C composite thin film prepared using ion beam co-sputtering technique[11,20-21]. However the synthesis system and processes are expensive and complicated, furthermore it is difficult to control the particles density. As one of the conventional techniques for fullerenes and carbon nanotubes synthesis[27-29], laser ablation technique provides a more convenient and simple platform for fabrication of M-C system, alloyed and metal-oxide-C composite system [22-24,29]. However empty carbon cages and carbon nanotubes are always synthesized accompanied with M-C particles using laser ablation method[29,30]. F. Dumitrache et al. achieved monodispersed carbon-coated iron particles with a sharp distribution by laser pyrolysis of volatile iron and carbon precursors in a gas flow reactor[22]. But its yield was very low. Different from conventional pulse laser techniques, which are usually equipped with a heating system or using a continue wave laser beam to ablate a M-C composite target [23-24, 28-29], this work uses a long pulse (usually $0.1 \sim 1.0 \mathrm{~ms}$ pulsed duration is adopted) laser to ablate a pure metal target in methane/helium gas mixture at room temperature. It is easy to achieve high yield of M-C particles with sharp distribution, and easy to control the spatial density of dispersed M-C particles, which is crucial for growth of high aspect ratio carbon nanotubes with M-C catalysts. Furthermore no 
carbon nanotubes and no empty carbon cages were found among M-C nanoparticles in this work.

In this work, we report a simple one-step synthesis method of carbon encapsulated nickel (Ni-C) nanoparticles using a long pulse laser to ablate a nickel target in methane or mixture of methane and helium at room temperature. By this method, high yield of core-shell structure Ni-C nanoparticles with typical size of $5 \mathrm{~nm}$ and size distribution of $3-10 \mathrm{~nm}$ were fabricated. We also demonstrated vertically aligned carbon nanotubes/nanofibers with low spatial density can be synthesized directly on a silicon substrate by controlling the surface spatial density of Ni-C nanoparticles catalysts.

\section{Experimental}

Carbon-encapsulated Ni nanoparticles have been fabricated by pulsed laser ablation at room temperature. A pulsed Nd:YAG laser $(\lambda=1064 \mathrm{~nm}$, repetition rate $\mathrm{f}=1 \sim 300 \mathrm{~Hz}$, pulse duration $\tau=0.1 \sim 20 \mathrm{~ms}$ and pulse energy $\mathrm{E}_{\mathrm{p}}=0.1 \sim 210 \mathrm{~J} /$ pulse) is used to ablate a pure $\mathrm{Ni}$ target(with purity of 99.99\%) in $\mathrm{He}$ or $\mathrm{He} / \mathrm{CH}_{4}$ mixture. The distance between the silicon substrate and the rotating nickel target was $6 \mathrm{~cm}$. Before experiment, the synthesis chamber was evacuated to a base pressure of $5 \mathrm{~Pa}$, and dilute twice by $\mathrm{He}$, then fill $\mathrm{He} / \mathrm{CH}_{4}$ mixture with a certain ratio to a wanted pressure. The laser beam was focused with an incident angle of $45^{\circ}$ on the targets, as shown in Fig.1. To explore the effect of $\mathrm{CH}_{4}$ concentration and gas pressure on graphite shell of nanoparticles, $\mathrm{CH}_{4}$ concentration and gas pressure change from $10 \%$ to $100 \%$ and $13 \mathrm{kPa}$ to $67 \mathrm{kPa}$ respectively, keeping the following parameters fixed, repetition rate $\mathrm{f}=10 \mathrm{~Hz}$, pulse duration $\mathrm{s}=0.1 \mathrm{~ms}$ and energy per pulse $1.8 \mathrm{~J} /$ pulse, laser spot on nickel target is $\sim 0.2 \mathrm{~mm}$ in diameter. The carbon-encapsulated Ni nanoparticles was characterized and analyzed with field emission scanning electron microscopy (FESEM), high resolution transmission electron microscopy (HRTEM), X-ray diffraction (XRD) and Raman spectrum.

\section{Results and discussion}

When the long pulse laser ablates the nickel target, the vaporization of nickel target and decomposition of methane occurred synchronously and a plasma plume consists of super high-density nickel vapor and decomposed carbon, hydrogen and helium species is produced. To analyze the formation process of core-shell structure Ni-C particles, we divide the pulse-duration plasma plume into three regions: vaporization, expansion, nucleation and condensation regions[31]. As for the cases of laser ablating metal-carbon composite target and arc discharging with metal-carbon composite cathode[2, 4, 29,30], in which both carbon and metal are vaporized and melted together carrying high energy. Therefore the carbon coating is mainly from metal-carbon composite vapor phase's separation. Because both carbon and metal are energy carriers, M-C nanoparticles formation is a hot metal catalysts-hot carbon source reaction process. Different from 
laser ablating metal-carbon composite target and arc discharging with metal-carbon composite cathode, for this work the vaporization region mainly consists of saturated nickel vapor with high temperature, which is the dominant energy carrier. The carbon coating is mainly from decomposition of ambient cold carbon source out of particles metal. Therefore here M-C nanoparticles formation is a hot metal catalysts-cold carbon source reaction process. In the expansion region, interpenetration and collisions between nickel atoms and ambient species give rise to methane mixing into nickel vapor and energy exchanging among them, the result is ionization, excitation and decomposition of ambient gases, and much energy loss from nickel atoms[32-34]. When the temperature of nickel vapor reduces to the critical point of condensation, nucleation occurred and nickel particles formed, and at the same time most of the dissolved carbon atoms are excluded to the surface from the nickel particles volume and the close available carbon atoms deposit onto the surface of nickel particles immediately in the nucleation region [22, 35-36]. As soon as the surface of nickel particles surrounded by carbon atoms, the graphitization of carbon coating occur till both the nickel particles temperature and ambient gases temperature reduce to less than the critical temperature of graphitization. As a result, graphene layers encapsulated nickel particles formed. In our previous results using dc arc discharges, we have observed the graphene layers encapsulated Ni nanoparticles [27]. Because the carbon coating prevents more nickel atoms participate in the existing nickel cores, small size and uniform nickel cores are available by pulse laser ablation.

Figure 2 shows the powder X-ray diffraction (XRD) pattern of the as-made Ni-C nanoparticles. The peaks at $2 \theta=26.24^{\circ}$ can be attributed to the diffractions of (002) planes of the hexagonal graphite structure. The broad diffraction signal from $20^{\circ} \sim 25^{\circ}$ is possible from disorder carbon. The peaks appearing at $2 \theta=44.32^{\circ}, 51.52^{\circ}$ and $76.28^{\circ}$ result from the diffractions of nickel (111), (200) and (220) planes respectively. The broad peaks from nickel diffractions indicate fine structure of nickel particles according to Sherrer effect. Through the calculation based on Sherrer equation [37], the average encapsulated nickel grain size of less than $3 \mathrm{~nm}$ can be estimated from the nickel diffraction peaks. However it is much smaller than the typical nickel particle size estimated by TEM, about $5 \mathrm{~nm}$. It suggests that most nickel particles are possible composed of more than one grain. The XRD pattern indicates the products of the present experiments consist of graphite carbon, disorder carbon, disorder and crystalline nickel.

Figure 3(a) shows the transmission electron microscopic (TEM) images of the as-made Ni-C nanopartilces. The typical size of particles is $5 \mathrm{~nm}$, and size distribution ranges from 3 to $10 \mathrm{~nm}$. As shown in Fig. 3(b), a magnified image of the selected area at Fig. 3(a) clearly indicates an encapsulation structure of several graphene layers surrounding a crystalline nickel core. It can be estimated from the inset image of Fig. 3(b) that the interlayer distance of crystalline Ni grain is about $0.20 \mathrm{~nm}$, corresponding to $\mathrm{Ni}(111)$ plane. Except for the carbon encapsulated Ni nanoparticles, there 
are no carbon nanotubes, empty carbon cages or other unwanted byproducts were found. It is also noticed that some particles are lightly agglomerated by the coalescence of the outer shells, forming complex long chains, which can be further confirmed by FE-SEM image of Ni-C particles(not shown here). This is probably because the magnetostatic energy of ferromagnetic nanoparticles can be minimized by such coalescence[38].

To have more about the phase's information of carbon coating, Raman spectra were used to characterize the Ni-C particles produced in different pressure with different $\mathrm{CH}_{4}$ concentration. Figure 4 shows the Raman spectrum of Ni-C particles. The D band at about $1335 \mathrm{~cm}^{-1}$ and $\mathrm{G}$ band at about $1598 \mathrm{~cm}^{-1}$ represent the amorphous carbon and graphite carbon components respectively [39]. A little weaker intensity of $G$ band than $D$ band means more than half of the carbon coating is amorphous structure on the surface of carbon coatings. Furthermore the intensity ratio of $\mathrm{G}$ band to $\mathrm{D}$ band weakly depends on the pressure in the range of $13 \mathrm{kPa} \sim 67 \mathrm{kPa}$ and $\mathrm{CH}_{4}$ concentration in the range of $10 \% \sim 100 \%$ in $\mathrm{He} / \mathrm{CH}_{4}$ mixture. Therefore, graphene encapsulated nickel nanoparticles are easy to produce by long pulse laser ablation method in wide range of $\mathrm{CH}_{4} / \mathrm{He}$ mixture pressure and $\mathrm{CH}_{4}$ concentration.

Carbon nanotubes (CNTs) as one of the most promising cold electron emitter materials for next generation flat panel displays have attracted much researching interest recent years. In order to achieve excellent emission performance, it is extensively studied to grow vertically aligned CNTs with high aspect ratio. Reference [16] reported cabon nanotubes/nanofibers were synthesized using monodispered carbon coated iron nanoparticles as catalysts. But only big bundles of ramdomly aligned nanotubes/nanofibers were achieved. Here we deposited Ni-C nanoparticles directly on a silicon substrate with low spatial density by laser ablation method as catalyst for growing high aspect ratio CNTs. The as-produced Ni-C particles have been exposed to air for 15 days before moving them into thermal CVD chamber to grow CNTs. The CVD chamber is a quartz tube with an inner diameter of $40 \mathrm{~mm}$ surrounded by a conventional electric furnace. The silicon substrate with low-density Ni-C catalysts on it which is set at the coaxial center of furnace and quartz tube is heated up to $850{ }^{\circ} \mathrm{C}$. Prior to CVD growth, the catalysts were pretreated with $\mathrm{NH}_{3}$ gas at a gas flow rate of $150 \mathrm{sccm}$ at $226 \mathrm{~Pa}$ for $5 \mathrm{~min}$. CNTs were then grown on the pretreated substrates under a flow of $\mathrm{C}_{2} \mathrm{H}_{2}$ and $\mathrm{NH}_{3}$ gas mixture with flow rate of $50 \mathrm{sccm}$ and $150 \mathrm{sccm}$ respectively at a pressure of $766 \mathrm{~Pa}$ for $10 \mathrm{~min}$. The above experimental parameters are the typical conditions for CNTs growth. The morphology of as-grown products was characterized by FESEM. As shown in Fig. 5, vertically aligned nanostructures with low spatial density have been directly grown on silicon substrate, which are possible CNTs or carbon nanofibers. The nanostructures are $\sim 1 \mu \mathrm{m}$ of length with $15 \sim 50 \mathrm{~nm}$ outer diameter distribution, where the spatial distribution corresponds to Ni-C catalyst distribution. Bunches of several nanostructures, even isolated single nanostructure can stand on the substrate with relative large distance to each other. However the diameter of 
nanostructures is much bigger than catalysts, because some very close nickel particles would melt together to form a bigger particles under high temperature. The phenomenon was demonstrated in other experiments using the same thermal CVD system (the results are not shown here). As a result, much bigger size and broader size distribution of nanostructures were grown. Because the carbon encapsulation besides protecting nickel particles from degradation also weakens the magnetostatic effect of nickel particles, which is usually result in agglomeration of ferromagnetic particles. It is possible to deposit dispersed Ni-C catalyst with low density on silicon substrate to reduce the spatial density of carbon nanostructures.

\section{Conclusions}

Core-shell structure Ni-C nanoparticles with typical size of $5 \mathrm{~nm}$ and size distribution between 3 and $10 \mathrm{~nm}$ were fabricated by using a focus laser beam to ablate a rotating nickel target in $\mathrm{CH}_{4} / \mathrm{He}$ mixture atmosphere at room temperature. Carbon encapsulated metal nanoparticles are easy to produce by long pulse laser ablation method in wide range of $\mathrm{CH}_{4} / \mathrm{He}$ mixture pressure and $\mathrm{CH}_{4}$ concentration. The growth of vertically aligned nanostructures with low spatial density has been demonstrated by thermal CVD using low density catalytic $\mathrm{Ni}-\mathrm{C}$ particles. Last but not the least, it is still very desired to fabricate narrower vertically aligned and low spatial density CNTs using much smaller graphene-encapsulated catalytic metal particles for applications as electron field emitter materials.

\section{Acknowledgement}

This work was supported by the Grants-in-Aid for Scientific Research and performed under the 21st Century COE Program, "Research and Education Center of Nanovision Science" by the Japan Society for the Promotion of Science. 


\section{Reference}

[1] M. Audier, J. Guinot, M. Coulon and L. Bonnetain, Carbon 19 (1981) 99.

[2] J. Jiao and S. Seraphin, J. Appl. Phys. 83 (1998) 2442.

[3] R. S. Ruoff, D. C. Lorents, B. Chan, R. Malhotra, S. Subramoney, Science, 259 (1993) 346.

[4] M. Tomita, Y. Saito and T. Hayashi, Jpn. J Appl. Phys. 32 (1993) L280.

[5] B. Diggs, A. Zhou, C. Silva, S. Kirkpatrick, N. T. Nuhfer, M. E. McHenry, D. Petasis, S. A. Majetich, B. Brunett, J. O. Artman and S. W. Staley, J. Appl. Phys. 75 (1994) 5879.

[6] E. M. Brunsman, R. Sutton, E. Bortz, S. Kirkpatrick, K. Midelfort, J. Williams, P. Smith, M. E. McHenry, S. A. Majetich, J. O. Artman, M. DeGraef and S. W. Staley, J. Appl. Phys. 75 (1994) 5882.

[7] S. A. Majetich, J. O. Artman, M. E. McHenry and N. T. Nuhfer, S. W. Staley, The American Physical Society, 48 (1993) 16845.

[8] S. Subramoney, Adv. Mater. 10 (1998) 1157.

[9] F. C. Fonseca, A. S. Ferlauto, F. Alvarez, G. F. Goya, R. F. Jardin, J. Appl. Phys. 97 (2005) 044313.

[10] H. Wang, S. P. Wong, W. Y. Cheung, N. Ke, and M. F. Chiah, H. Liu and X. X. Zhang, J Appl Phys 88 (2000) 2063.

[11] T. Hayashi, S. Hirono, M. Tomita, and S. Umemura, Nature, 38 (1996) 772.

[12] D. K. Kim, Y. Zhang, J. Kehr, T. K. Lason, B. Bjelke, M. Muhammed, J. Magn. Mater. 225 (2001) 30 .

[13] M. Bloemer and J. W. Haus, Appl. Phys. Lett. 61 (1992) 1619.

[14] X.G. Gong, Q.Q. Zheng, Y.Z. He, Phys. Lett. A 181 (1993) 459.

[15] Y.H. Yao, X. Gu, M. Ji, X.G. Gong, Ding-sheng Wang, Phys. Lett. A 360 (2007) 629.

[16] D. Babonneau, F. Pailloux, J.P. Eymery, M.F. Denanot, P. Guérin, E. Fonda, O. Lyon, Phys. Rev. B 71 (2005) 035430.

[17] J. H. J. Scott, S. A. Majetich. Morphology, Phys Rev B 52 (1995) 12564.

[18] S. Seraphin, D. Zhou, J.Jiao, J Appl Phys 80 (1996) 2097.

[19] V. P. Dravid, J. J. Host, M. H. Teng, B. E. Jinha, H. D. Lynn, J. Thomas, O. Mason and J. R. Weertman, Nature 374 (1995) 602.

[20] D. Babonneau, J. Briatico, F. Petroff, T. Cabioc'h, and A. Naudon, J. Appl. Phys. 87(2000) 3432.

[21] D. Babonneau, J. Toudert, S. Camelio, F. Pailloux, T. Cabioc'h, and T. Girardeau, Surf. Coat. Technol. 200 (2006) 6251.

[22] F. Dumitrache, I. Morjan, R. Alexandrescu, R. E. Morjan, I. Voicu, I. Sandu, I. Soare, M. Ploscaru, C. Fleaca, V. Ciupina, G. Prodan, B. Rand, R. Brydson, A. Woodword, Diam. Relat. Mater. 13 (2004) 362. 
[23] N. M. Dempsey, L. Ranno, D. Givord, J. Gonzalo, R. Serna, G. T. Fei, A. K. Petford-Long, R.

C. Doole, and D. E. Hole, J. Appl. Phys. 90 (2001) 6268.

[24] H. W. Kroto, J. R. Heath, S. C. O'Brien, R. F. Curl and R. E. Smalley, Nature, 318 (1985) 162.

[25] S. Iijima, Nature, 354 (1991) 56.

[26] M. Nagatsu, T. Yoshida, M. Mesko, A. Ogino and T. Matsuda, T. Tanaka, H. Tatsuoka, K. Murakami, Carbon, 44 (2006) 3336.

[27] Z C Ying, R L Hettich, R N Compton and R E Haufler, J. Phys. B: At. Mol. Opt. Phys. 29 (1996) 4935.

[28] L. C. Qin, S. Iijima, Chem. Phys. Lett. 269 (1997) 65.

[29] F. Kokai, K. Takahashi, M. Yudasaka, R. Yamada, N. Sensui, T. Ichihashi, and S. Iijima, J. Phys. Chem. B 103 (1999) 4346.

[30] W. K. Maser, E. Muñoz, A. M. Benito, M. T. Martínez, G. F. de la Fuente, Y. Maniette, E. Anglaret and J. -L. Sauvajol, Chemical Physics Letters, 292 (1998) 587.

[31] M. S. Tillack, D. Blair and S. S. Harilal, Nanotechnology 15 (2004) 390.

[32] G. De Boer, S. Arepalli, W. Holmes, P. Nikolaev, C. Range, C.D. Scott, J. Appl. Phys. 89(2001) 5760.

[33] A. A. Puretzky, D. B. Geohegan, X. Fan, S. J. Pennycook, Appl. Phys. A 70 (2000) 153.

[34] A. A. Puretzky, D. B. Geohegan, X. Fan, S. J. Pennycook, Appl. Phys. Lett. 76 (2000) 182.

[35] M. Yudasaka, T. Komatsu, T. Ichihashi, Y. Achiba, and S. Iijima, J. Phys. Chem. B 102 (1998) 4892.

[36] R. L. Vander Wal, G. M. Berger and T. M. Ticich, Applied Physics A, 77 (2003) 885.

[37] F. W. Jones, J. Sci. Instrum. 18 (1941) 157.

[38] C. J. Choi, X. L. Dong and B. K. Kim, Scr. Mater. 44 (2001) 2225.

[39] F. Kokai, K. Takahashi, D. Kasuya, A. Nakayama, Y. Koga, M. Yudasaka, S. Iijima, Appl. Phys. A, 77 (2004) 69. 


\section{Figure Captions}

Fig.1. Schematic diagram of pulse laser ablation apparatus.

Fig.2 X-ray diffraction pattern of Ni-C nanoparticles fabricated in $67 \mathrm{kPa} \mathrm{He} / \mathrm{CH}_{4}$ mixture with $50 \% \mathrm{CH}_{4}$ concentration.

Fig.3 (a)HRTEM image and (b) a magnified image of Ni-C nanoparticles produced in $67 \mathrm{kPa}$ $\mathrm{He} / \mathrm{CH}_{4}$ mixture with $50 \% \mathrm{CH}_{4}$ concentration.

Fig.4 Raman spectrum of Ni-C particles.

Fig.5 FESEM image of CNTs synthesized by thermal CVD using Ni-C catalyst. 


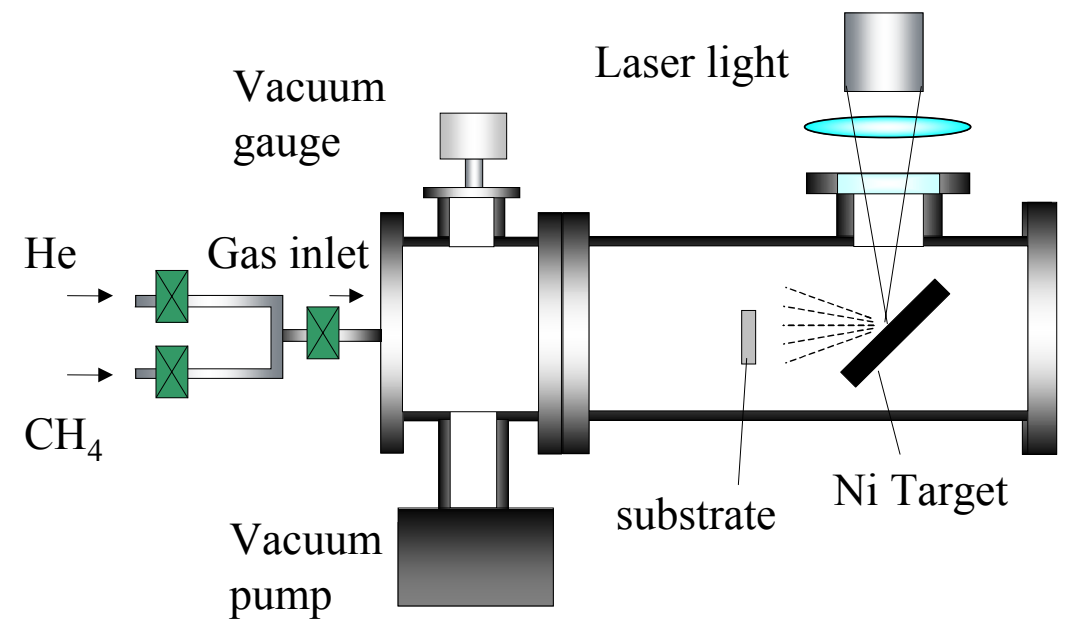

Fig. 1 Q. Ou, et al. 


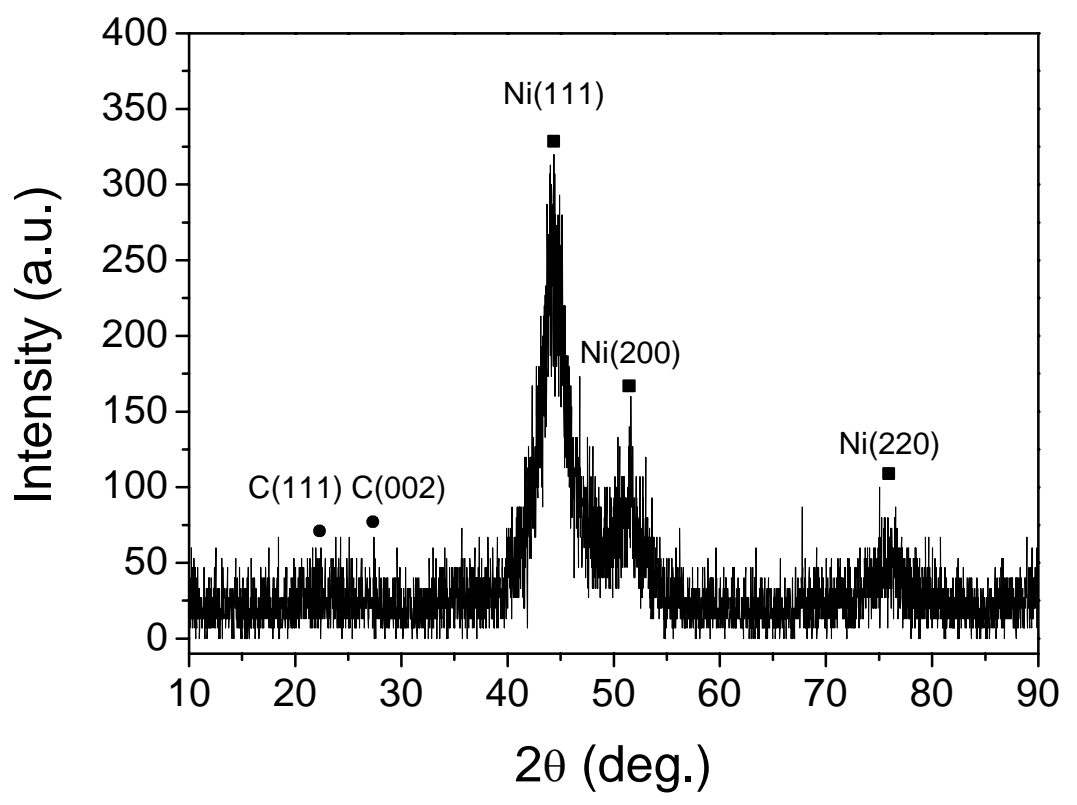

Fig. 2 Q. Ou, et al. 

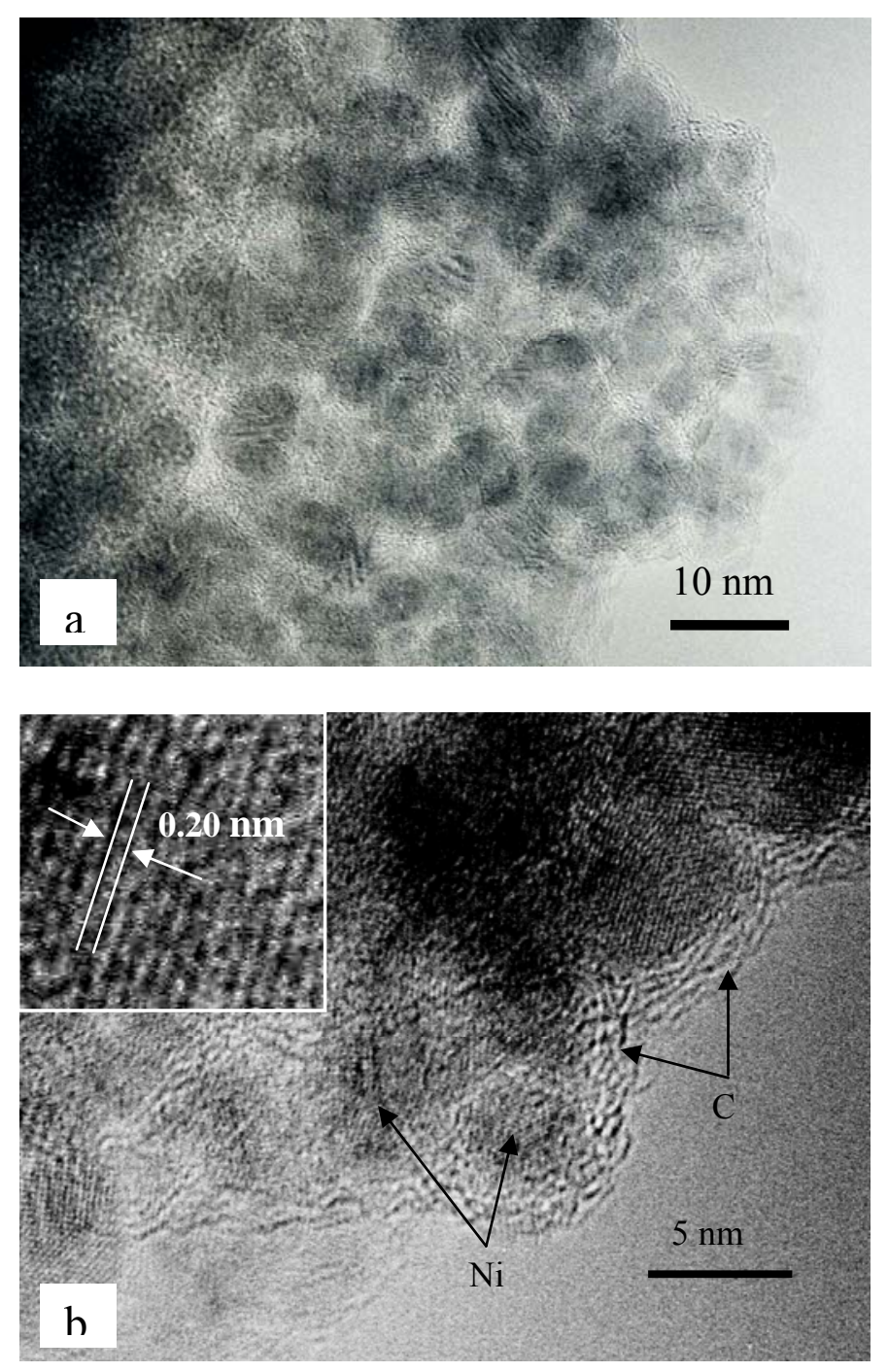

Fig. 3 Q. Ou, et al. 


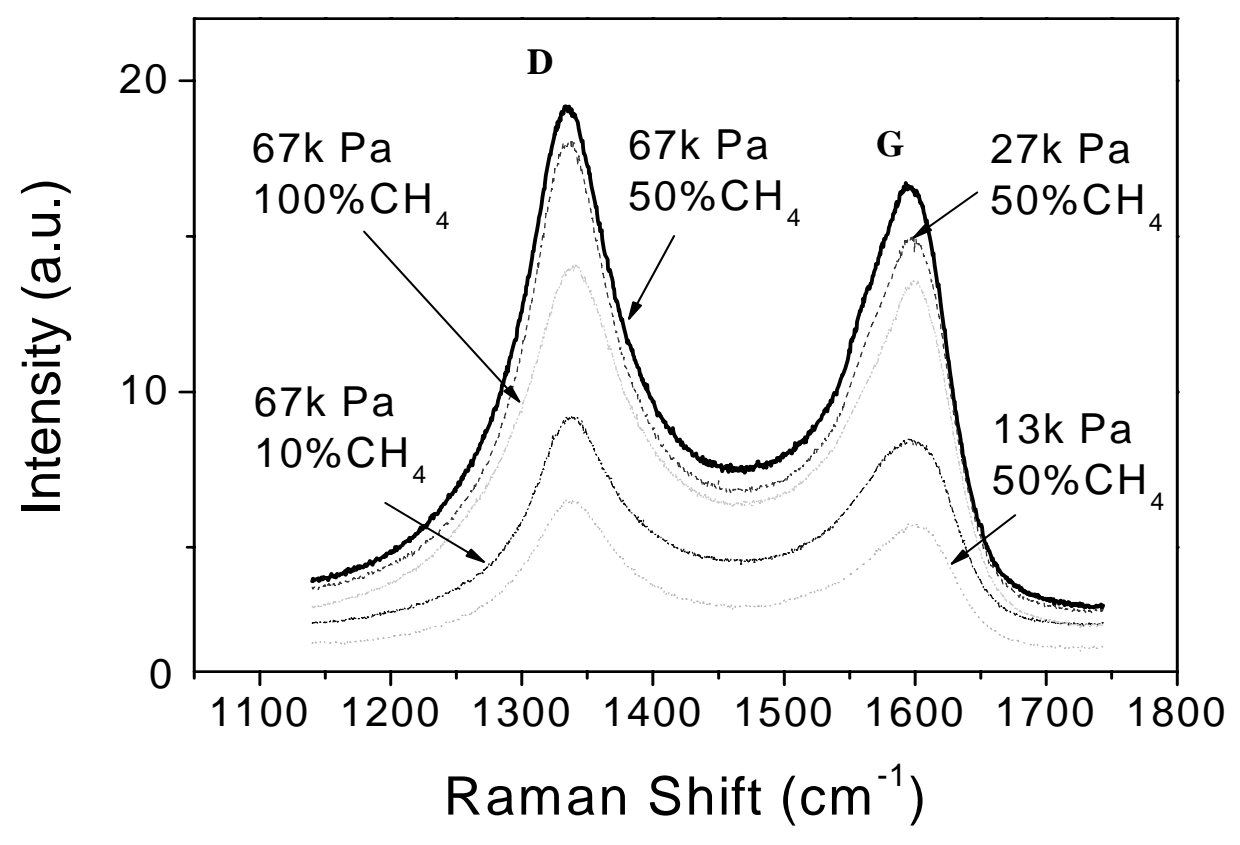

Fig. 4 Q. Ou, et al. 


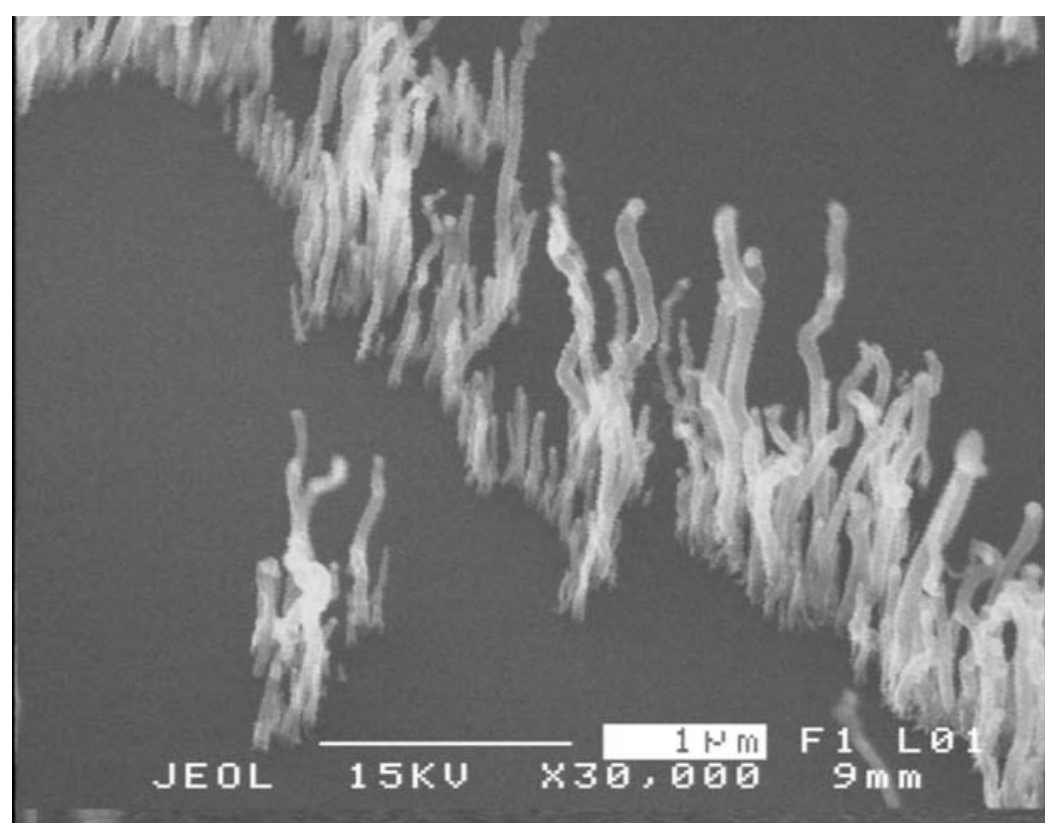

Fig. 5 Q. Ou, et al. 